\title{
Antifeedant activity of Vernonia oocephala against stored product pest Tribolium casteneum (Herbst)
}

\author{
A.B. Aliyu ${ }^{{ }^{*}}$, M.M.H. Adeyemi ${ }^{2}$, I. Abdulkadir ${ }^{1}$, M.B. Dambatta ${ }^{1}$, J.O. Amupitan $^{1}$, A.O. Oyewale ${ }^{1}$ \\ ${ }^{1}$ Department of Chemistry, Ahmadu Bello University, Zaria-Nigeria \\ ${ }^{2}$ Industrial Chemical Division (R\&D), National Research Institute for Chemical Technology (NARICT) Basawa, \\ Zaria-Nigeria
}

\begin{abstract}
In recent years botanical antifeedants have received increasing attention in developing countries due to continued damaging of grains associated to post harvest insect pest. To develop a sustainable management of post harvest pest using local plant resources in Nigeria, Vernonia oocephala ethanol extract, chloroform and petroleum ether fractions were subjected to antifeedant activity against the stored product pest (in maize and maize flour products) Tribolium casteneum (Herbst). Wheat wafer disc technique was used in the experiment. The feeding deterrence expressed as Feeding inhibition rate $[\mathrm{FI}](\%)$, indicates that ethanol extract was most potent against the insect with a range of $54 \pm 1.43$ to $86 \pm 1.2 \%$ and moderate activity of $50 \pm 1.11$ to $70 \pm 3.12 \%$ was observed in the chloroform fraction. Phytochemical screening revealed the presence of flavonoids, glycoside, saponins, steroids and triterpenes, cardiac glycoside and tannins in addition; sesquiterpene lactones were identified from chloroform fraction. These findings indicate the potential utility of extracts and fraction of Vernonia oocephala for developing active botanical pesticides against the pest Tribolium casteneum
\end{abstract}

Keywords: Antifeedant; Vernonia oocephala; Botanical pesticides; Tribolium casteneum

\section{Introduction}

Plant-derived insecticides have great potential for natural control of post-harvest insect pests, particularly in tropical countries like Nigeria. This stands more important due to increasing incidence of insect resistance against chemical insecticides. Chemical control of stored product-pest has been used for a long time (Isman, 1997). This control measure constitutes problems due to indiscriminate use leading to genetic resistance of pest species (Khanam et al. 1990). In addition, synthetic insecticides have in many cases only produced moderate results along with major ecological damages (Franzen, 1993).

Tribolium casteneum (Herbst) is a pest which infests maize crops in the farm and carried into storage where insect population increases (Appert 1987; Adedire and Lajide, 2003). The manifest consequences are the gradual depletion of food quality over storage time resulting to poor products. Hence, the post-harvest loss (PHL) due to the pest attack and other factors in developing countries posed threats to food security (Anomymous, 2011). The need for effective albeit safe control measures of post-harvest pest is imperative. This can be achieved through qualitative research and development (R\&D) strategy on botanic based pesticides, which have been found to act concertedly on both behavioural activities and physiological processes of insect pest (Saxena, 1987). In addition, botanic pesticides have been proven to be specific in action to target pest and relatively harmless to non-target organisms including humans (Golob and Webley, 1980).

Vernonia oocephala Baker (Asteraceae) is an erect under shrub, about 1-2 feet high, with branches from near the base and whitish florets in numerous crowded straw-coloured head of about half inch long. It is perennial and distributed across Northern part of Nigeria (Hutchinson and Dalziel, 1963). Several species belonging to the Vernonia genus are known for numerous medicinal uses in traditional medicine across Africa. Some of them including $V$. amygdalina, $V$. colorata, $V$. cinerea and $V$. blumeoides have been reported for antitrypanosomal, antibacterial and insect antifeedant activities (Tandon et al., 1998; Rabe et al., 2002; Aliyu et al., 2011; Yusuf et al., 2012; Ibrahim et al., 2013) among others. Chemical and biological studies of protective allelochemicals especially those affecting insects feeding can make an important contribution to future efforts to control the damage of the crops caused by the insects. To explore the use of plant resources for effective insect post harvest management, this study was designed to evaluate the antifeedant activity of crude extract and fractions of Vernonia oocephala against T. casteneum which had not been reported hitherto.

*Corresponding author: E-mail: aliyubabando@gmail.com 


\section{Materials and methods}

\section{Collection and preparation of plant material}

The plant $V$. oocephala was collected from a local area of Zaria, Kaduna state, on 13th August, 2010. It was authenticated at the herbarium of the Department of Biological Sciences, Ahmadu Bello University, Zaria. A voucher specimen number (1334) was deposited there. The leaves were air-dried and sample pulverized with mortar and pestle to powdered form.

\section{Extraction of plant material}

The powdered plant sample (500 g) was percolated using $95 \%$ ethanol solution $(800 \mathrm{ml})$ in a closed container on a shaker for $48 \mathrm{hr}$. It was filtered and the filtrates was then concentrated at reduced pressure to dryness using rotary evaporator at $45^{\circ} \mathrm{C}$.

\section{Phytochemical screening}

Phytochemical screening of the crude extract and fractions was carried out to detect the presence of secondary metabolites by using standard procedures of Sofowora (Sofowora 1993).

Test for glycoside $\left(\mathrm{FeCl}_{3}\right.$ test): To small portion of the extract conc. $\mathrm{H}_{2} \mathrm{SO}_{4}(5 \mathrm{ml})$ was added to the extract and boiled for 5 minutes. This was then cooled, neutralized with $20 \% \mathrm{KOH}$ and divided into two (2) portions. Three (3) drops of ferric chloride solution were added to one of the portions giving a green to black precipitate which indicated phenolic aglycone as a result of hydrolysis of glycoside.

Test for cardiac glycosides (Kella-Killiani test): Small portion of extract was dissolved in glacial acetic acid containing traces of $5 \%$ ferric chloride. The test tube was held at an angle of $45^{\circ}$ and conc. $\mathrm{H}_{2} \mathrm{SO}_{4}(1 \mathrm{ml})$ was added down the side. A purple colour at the interfaces indicated cardiac glycoside.

Test for saponins (Frothing test): Small quantity of the extract was dissolved in distilled water $(10 \mathrm{ml})$. This was then shaken vigorously for 30 seconds. and allowed to stand for 15 min. A form for more than $30 \mathrm{~min}$ indicated the presence of saponins.

Test for steroids and triterpenes (Lieberman-Burchard's test): To the solution of extract $(2 \mathrm{ml})$ was added acetic anhydride $(2 \mathrm{ml})$ followed by conc. $\mathrm{H}_{2} \mathrm{SO}_{4}(1 \mathrm{~m} \mathrm{l})$ was added downside the tube and the color change was recorded immediately and later. Red, pink or purple color indicates the presence of triterpenes while blue or blue-green indicates steroids.

Test for flavonoids $(\mathrm{NaOH}$ test): To the extract aqueous solution $(5 \mathrm{ml})$ in a test tube, three drops of aqueous $\mathrm{NaOH}$ were added, the formation of and a yellow coloured solution indicated the presence of flavonoids.

Test for tannins (Ferric chloride test): Sample extract (0.5 g) was dissolved in distilled water $(10 \mathrm{ml})$ and filtered. Four drops of ferric chloride solution were added to filtrate. Formation of a blue-black precipitate indicated the presence of hydrolysable tannins while the presence of green precipitate indicated the presence of condensed tannins.

Test for alkaloids (Dragendorf's test): To the extract solution in a test tube, four drops of the Dragendorf's reagent were added; a red precipitate indicated the presence of alkaloids.

\section{Preparation of sesquiterpene lactones fraction}

Sesquiterpene lactones fraction was isolated as described by Doskotch and co-workers (Doskotch and El-feraly, 1969). The ethanol extract (20 g) was suspended in water and partitioned with equal amount of chloroform in a separatory funnel. The chloroform portion was further fractionated between $10 \%$ methanol and petroleum ether. The aqueous methanol portion was also subjected to fractionation between equal amount of chloroform and water to obtain the sesquiterpene lactone fraction given by the flow chart below:

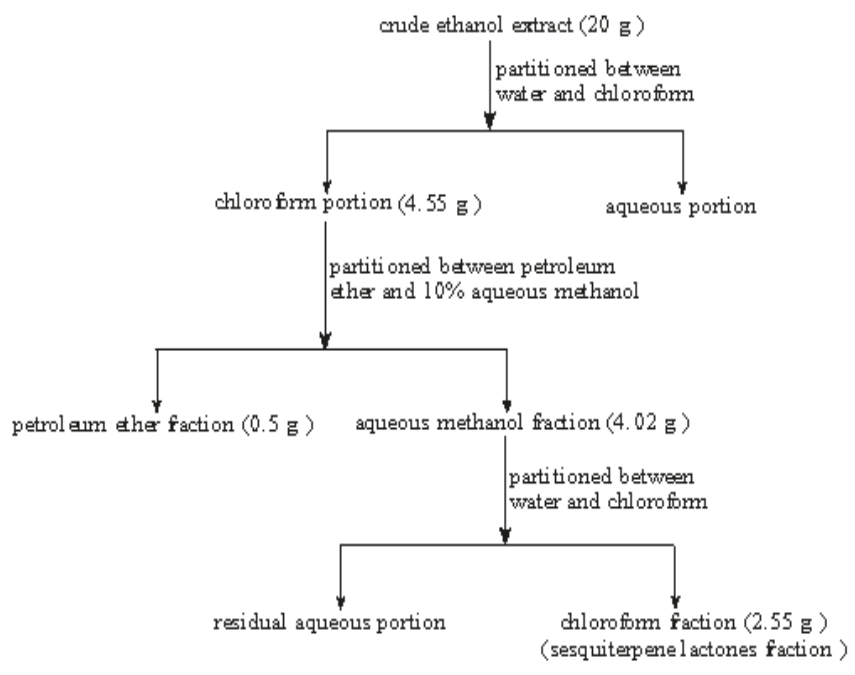

Test for sesquiterpene lactones (Baljet Reagent)

The chloroform fraction (10 mg) was tested using 2 drops of $1: 1$ ratio of $1 \%$ picric acid in ethanol and $10 \%$ sodium 
hydroxide. The appearance of orange colour indicated the presence of sesquiterpene lactones (SLs) (Sliva et al., 1998).

\section{Insect culture}

The experimental insects were reared under laboratory conditions at $27 \pm 2 \mathrm{oC}$ on a diet mixture of wheat meal $(190$ g) whole meal wheat flour and brewer's yeast $(10 \mathrm{~g}$, [19:1]).Test organisms used were starved for 36-48 hr before being introduced into the containers containing the prepared wafer discs (Talukder and Howse, 1995).

\section{Preparation of wheat wafer discs}

Wheat wafer discs, made of finely ground flour and water baked at $80 \mathrm{oC}$ were used as the test food or substrate. The discs used in the antifeedant bioassay were within range of $0.30-0.35 \mathrm{~g}$.

\section{Antifeedant activity test}

The antifeedant bioassay of Vernonia oocephala extract and fractions was determined using the wheat wafer disc technique (Talukder and Howse, 1995; Morimoto et al., 2006). The feeding deterrence test measures the activity of the test compounds or extracts using the antifeedant index (AFI). The AFI is a measure of the percentage of the weight of the treated wafer discs consumed in comparison with the untreated wafer discs as stated below:

$$
\mathrm{AFI}=\frac{\% \text { weght of treated disc consumed } \times 100}{\% \text { weght of treated disc consumed }+\% \text { weight of control disc consumed }}
$$

The AFI values obtained are then converted to the feeding inhibition rate FI (\%)

$$
\mathrm{FI}(\%)=(50-\mathrm{AFI}) \times 2 .
$$

A negative control using phostoxin, aluminium phosphide, the primary post harvest chemicals used on maize for stored off-farm product was used as the control in the experimental procedure. Although aluminium phosphide is commonly referred to as a fumigant, it is used to kill adult insects, insect larvae, and mites and is classified as an insecticide by the Environmental Protection Agency (EPA) USDA Report (Anomymous, 2004).

\section{Statistical Analysis}

All experiments were carried out in triplicates. The results are given as mean \pm standard deviation (SD). Student's t-test was used for comparison between two means. Analysis of Variance (ANOVA) was used for more than two means. A difference was considered statistically significant when $\mathrm{p} \leq 0.05$.

\section{Results and discussion}

The results of phytochemical screening indicate the presence of flavonoids, glycosides, saponins, alkaloids and tannins in ethanol crude extract. The chloroform fraction gave a positive test for sesquiterpene lactones, hence referred to as 'lactone rich fraction', whereas the petroleum ether fraction was found to contain only steroids and triterpenes (Table I). Several plant extracts and isolated compounds containing alkaloids, diterpenes, monoterpenes, sesquiterpene lactones and phenolics compounds have been reported for varying degrees of insect deterrents activity (Adeyemi, 2010). This indicates that $V$. oocephala extracts may show some promise due to various secondary metabolites detected (Table I). The results in Table 2 show the antifeedant activity of ethanol extract and lactone rich fraction of $V$. oocephala. The ethanol extract showed maximum activity of $86 \%$ at higher concentration. This could be due to glycosides, saponins and alkaloids detected in the ethanol extract (Table 1). The lactone rich fraction however, showed interesting activity with $70 \%$ and the least feeding inhibition rate of $54 \%$ was observed with the petroleum ether fraction. It was however, observed that increase in concentration of the extract/fraction resulted to increase in the antifeedant activity. The activity between low and high concentrations was also statistically significant $(\mathrm{P} \leq$ 0.05) suggesting that the antifeedant activity was concentration-dependent (fig. 1).

Chemical characteristics such as functional groups and stereochemistry are important to feeding deterrent ability of a pure compound, such as triterpenoids based on the C-30 structural moiety existing as highly oxygenated derivatives often as glycosides; steroidal saponins or cardenolides are found to be potent antifeedants (Isman, 2002). This implies the functional roles of glycosides moieties in providing the effective toxicity to deter insect feeding. Therefore, the strong deterrent activity of ethanol extract may be due to glycosides containing components (Table I and II). Similarly, the presence of bitter principles such as sesquiterpene lactones in Vernonia species has been implicated for their biological activity. This is due to structural characteristics of the a-methylene- $\gamma$-lactone moiety (Chaturvedi, 2011). The chloroform fraction of $V$. occephala contained sesquiterpene lactones whose antifeedant potency agreed with earlier investigation where sesquiterpene lactone, glaucolide A isolated from $V$. glauca had been identified to be effective antifeedant agent (Burnett et al., 1974).

Volatile chemical components from plants such as monoterpenes or essential oils are important bioresources as insect deterrent agents perhaps due to characteristics lipophilic chemistry. Asawalam and co-workers (Asawalam 
Table 1: Results of the phytochemical screening

\begin{tabular}{|c|c|c|c|c|c|}
\hline Constituents & Test & $\begin{array}{l}\text { Ethanol } \\
\text { extract }\end{array}$ & $\begin{array}{l}\text { Pet ether } \\
\text { fraction }\end{array}$ & $\begin{array}{l}\text { Chloroform } \\
\text { fraction }\end{array}$ & \\
\hline Flavonoids & $\mathrm{NaOH}$ & & + & - & - \\
\hline Glycoside & $\mathrm{FeCl}_{3}$ & & + & - & - \\
\hline Saponins & Frothin & & + & - & - \\
\hline Steroids and Triterpenes & Lieber & lard's test & + & + & + \\
\hline Cardiac glycoside & Kella-k & & + & - & - \\
\hline Alkaloids & Dragen & & + & - & + \\
\hline Tannins & $\mathrm{FeCl}_{3} \mathrm{t}$ & & + & - & - \\
\hline
\end{tabular}

Key: $+=$ positive, $-=$ negative

Table 2: Results of Feeding inhibition rate $(\%)$

\begin{tabular}{lrccc}
\hline $\begin{array}{c}\text { Concentrations } \\
(\mathrm{mg} / \mathrm{ml})\end{array}$ & $\begin{array}{l}\text { Ethanol } \\
\text { extract }\end{array}$ & $\begin{array}{c}\text { Pet ether } \\
\text { fraction }\end{array}$ & $\begin{array}{c}\text { Chloroform } \\
\text { fraction }\end{array}$ & $\begin{array}{c}\text { Phostoxin (standard) } \\
\text { pesticide }\end{array}$ \\
\hline 0.01 & $86 \pm 1.20$ & $70 \pm 3.12$ & $53 \pm 1.21$ & ND \\
0.05 & $74 \pm 2.00$ & $66 \pm 2.43$ & $45 \pm 2.17$ & ND \\
0.1 & $54 \pm 1.43$ & $50 \pm 1.11$ & $38 \pm 1.90$ & $60 \pm 1.94$ \\
\hline
\end{tabular}

ND: Not determined, FI $(\%)$ were presented \pm Standard deviation of triplicate determinations

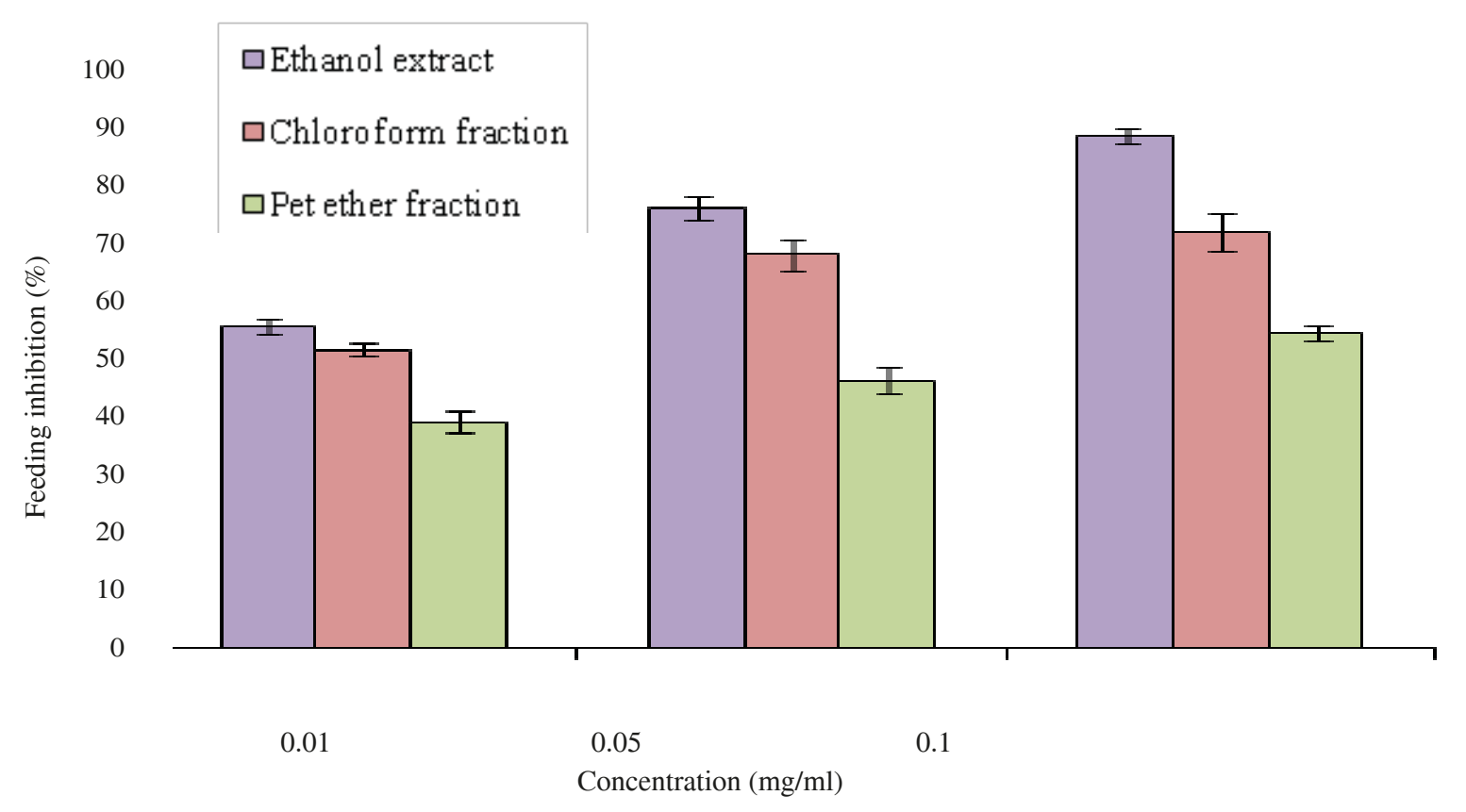

Fig. 1. Antifeedant activity of Vernonia oocephala 
and Hassanali, 2006) have demonstrated the repellent ability of $V$. amygdalina essential oil containing 1, 8-cineole, $\beta$-pinene, and myrtenal against maize weevil. This indicates that $V$. oocephala might contain some of these terpenoid chemo-types with repellent ability that presumably enhanced the antifeedant activity. It is also suggestive that the activity of both the lactone rich fraction and ethanol extracts may have been mediated by synergistic interactions of the various chemical components. The potency of crude ethanol extracts $>$ lactone rich fraction $>$ petroleum ether fraction. Our results have re-affirmed the potential utility of Vernonia species as plant based alternatives to insect post-harvest management. This is because the extract/lactone rich fraction of $V$. oocephala $(0.01 \mathrm{mg} / \mathrm{ml})$ was comparable $(\mathrm{P} \leq 0.05)$ to standard pesticide-phostoxin (aluminum phosphide) at low concentration, which indicates the significance of the extracts or chemical constituents in formulating effective bio pesticides against $T$. casteneum.

\section{Conclusion}

In this study Vernonia oocephala extracts and fraction have shown considerably moderate to good antifeedant activity against post-harvest insects $T$. casteneum using the wheat wafers disc technique, and the chemical components such as triterpenoids, phenolic compounds, glycosides and sesquiterpene lactones have been tested to be present. These compounds may also be analytically quantified from the extracts/fraction to provide the basis for formulation of optimally potent bio pesticides. However, isolation and characterization of pure compounds could be interesting trend of this research.

\section{Aknowledgements}

To Ahmadu Bello University, Zaria-Nigeria for financial support and the National Research Institute for Chemical Technology (NARICT)- Basawa, Zaria-Nigeria for providing some of the facilities.

\section{References}

Adedire CO and Lajide L (2003), Ability of Extracts of ten tropical plant species to protect maize grains against infestation by the maize weevil, Sitophilius zeamais during storage. Nig. J. Expt. Biol. 4: 175-179.

Adeyemi MMH (2010), The potential of secondary metabolites in plant material as deterrents against insect pests: A Review. Afr. J. Pure Appl. Chem. 4(11): 243-246.
Aliyu AB, Musa AM, Abdullahi MS, Ibrahim H, Oyewale AO (2011), Phytochemical screening and antibacterial activities of Vernonia ambigua, Vernonia blumeoides and Vernonia oocephala (Asteraceae). Acta Pol. Pharm. 68(1): 67-73.

Appert J (1987), The storage of food grains and seeds. The tropical agriculturalist CTA, (Macmillan Publishers Ltd, London) 1987, pp. 146.

Asawalam EF and Hassanali A (2006), Constituents of the essential oil of Vernonia amygdalina as maize weevil protectants. Trop. Subtrop. Agroecosyst. 6: 95-102.

Burnett W, Jones S, Mabry TJ and Padolina W (1974), Sesquiterpene lactones-insect feeding deterrents in Vernonia. Biochem. Syst. Ecol. 2: 25-29.

Chaturvedi D (2011), Sesquiterpene lactones: Structural diversity and their biological activities. Opportunity, Challenge and scope of Natural Products in Medicinal Chemistry, pp. 313-334.

Doskotch RW and El-Feraly FS (1969), Antitumor agents II: Tulipinolide, a new germacranolide sesquiterpene and costunolide. Two Cytotoxic substances from Liriodendron tulipefera L. J. Pharm. Sci. 58: 877-880.

Franzen H (1993), Need for development of new strategies for locust control in: New control for Locust control. Ed: Renbold, (Bona) 1993:89. pp. 9-13.

Golob P and Webley DJ (1980), The use of plants and minerals as traditional protectants of stored products. Tropical products institute G 138. Now Post harvest Pest and Quality section, Natural Resources Institute, Chatham, United Kingdom.

Hutchinson J and Dalziel JM (1963), Flora of West Tropical Africa, 2nd Edn.Vol. 2, (Crown Agents for Oversea Government and Administration, Millbank, London S. W. I.) 1963, pp. 276-277.

Ibrahim MA, Aliyu AB, Abdullahi H, Solomon T, Toko E, Garba A, Bashir M, Habila N (2013), Lactone-rich fraction from Vernonia blumeoides: antitrypanosomal activity and alleviation of the parasite-induced anemia and organ damage. J. Nat. Med. 67(4): 750-757.

Isman M (2002), Insect Antifeedants: In Pesticide Outlook. Royal Soc. Chem. 152-157.

Isman MB (1997), Neem and other botanical insecticides: Barriers to commercialization. Phytoparasitica. 25: 339-344. 
Khanam LAM, Talukder D and Khan AR (1990), Insecticidal property of some indigenous plants against Tribolium contusum Duval, (Coleoptera, Tenebrionidae). Bangladesh J. Zool. 18(2): 253-256.

Morimoto M, Fukumoto H, Hiratani M, Chavasir W and Komai K (2006), Insect antifeedants, Pterocarpans and Pterocarpol in Heartwood of Pterocarpus macrocarpus Kruz. Biosci. Biotechnol. Biochem. 70(8): 1864-1868.

Rabe T, Mullholland D and van Staden J (2002), Isolation and identification of antibacterial compounds from Vernonia colorata leaves. J. Ethnopharmacol. 80(1):91-94.

Saxena RC (1987), Antifeedants in tropical pest management. Insect Sci. Appl. 8: 731-736.

Sliva GL, Lee I and Kinghorn AD (1998), Special problems with the extraction of plants. In: Cannell, R.J.P.(Ed). Methods in Biotechnology: Natural Products Isolation Vol. 4. (Humana Press Inc. Totowa, NJ) 1998, pp. 357.

Sofowora A (1993), Medicinal plants and Traditional medicine in Africa. (Spectrum Books Ltd, Ibadan, Nigeria) 1993, pp. 289.

Talukder FA and Howse PE (1995), Evaluation of Aphanamixis polystachya as a source of repellant, antifeedants, toxicants and protectants in storage against Tribolium castaneum (Herbst). J. Stored Prod. Res. 31(1): 55-61.
Tando M, Shukla YN, Tripathi AK and Singh SC (1998), Insect Antifeedant principles from Vernonia cinerea. Phytother. Res. 12:195-199.

Anomymous, USDA Report (2004), Agricultural chemical usage post-harvest applications- Corn and Soybeans. March 2004. pp. 1-34.

Anomymous, World Bank 2011, Missing Food: The case of Postharvest Grain Losses in Sub-Saharan Africa. Economic and Sector work, (Washington DC 20433) Report Number 60371-AFR.

Yusuf AB, Umar IA, Musa UB and Nok AJ (2012), Screening of Vernonia amygdalina and Hymenocardia acida extracts and 1, 3-diaminopropane for their antitrypanosomal activities: In vitro model. J. Med. Plants Res. 6(19): 3573-3578.

Received: 1 January 2014; Revised: 6 July 2014; Accepted: 25 August 2014. 